\title{
Qualidade de processamento de tubérculos de batata produzidos sob diferentes disponibilidades de nitrogênio
}

\author{
Potato processing quality of tubers grown under different nitrogen availabilities \\ Viviani Ruffo de Oliveira ${ }^{1}$ Jerônimo Luiz Andriolo ${ }^{2}$ Dilson Antônio Bisognin ${ }^{3}$ \\ Adalberto Luiz de Paula ${ }^{1}$ Ana Paula Trevisan ${ }^{4}$ Rose Beatriz Antes ${ }^{4}$
}

\section{RESUMO}

O objetivo do trabalho foi determinar o teor de matéria seca e a coloração de chips de batata da cultivar Asterix produzidos sob cinco níveis de nitrogênio. O plantio foi feito em 02/09/2003, na UFSM, em sacolas com 4,4dm ${ }^{3}$ de substrato comercial. Os tratamentos foram constituídos por cinco soluções nutritivas com doses de $N$ de 5,0 (T1), 8,3 (T2), 11,3 (T3), 14,3 (T4) e 16,3mmol L-1 (T5). Os tubérculos foram colhidos em 17/12/2003, aos 104 dias após o plantio, e após 15 dias na temperatura de $20^{\circ} \mathrm{C}$ foram determinados o teor de matéria seca e a coloração dos chips. O teor de matéria seca dos tubérculos aumentou da primeira até a terceira dose, decrescendo a seguir segundo um modelo polinomial. Os valores foram de 19,5;20,5; 20,8; 18,6 e 18,4g 100g-1 nas doses de T1 a T5, respectivamente. Somente os tubérculos produzidos com as doses T2 e T3 atingiriam o teor mínimo de matéria seca preconizado pela literatura, que é de $20 \mathrm{~g} 100 \mathrm{~g}^{-1}$. Não houve relação entre a coloração dos chips $e$ as doses de $N$ fornecidas. Concluiu-se que o $N$ pode reduzir o teor de matéria seca dos tubérculos e que critérios específicos de manejo da adubação nitrogenada devem ser observados para a produção de tubérculos destinados ao processamento industrial.

Palavras-chave: Solanum tuberosum, chips, nutrição mineral, matéria seca.

\section{ABSTRACT}

The goal of the work was to determine dry matter content and chip color of potato tubers, cultivar Asterix, grown under five $N$ levels. Tubers were planted in bags with $4.4 \mathrm{dm}^{-3}$ of a commercial substrate, on September $2^{\text {nd }}, 2003$, at UFSM, RS, Brazil. Treatments consisted of five nutrient solutions with $N$ concentrations of 5.0 (T1), 8.3 (T2), 11.3 (T3), 14.3 (T4) and $6.3 \mathrm{mmol} \mathrm{L} \mathrm{L}^{-1}$ (T5). Tubers were harvested on December $17^{\text {th }}, 2003$, at 104 days after planting. Tubers were stored during 15 days before determinations of dry matter and chip color. Dry matter content increased in tubers from T1 to T3 and decreased thereafter, following a polynomial model. Dry matter

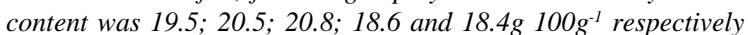
from $T 1$ to $T 5$. Tubers produced with $T 2$ and $T 3 \mathrm{~N}$ levels reached the minimum dry matter content $\left(20 \mathrm{~g} 100 \mathrm{~g}^{-1}\right)$ indicated in the literature. $N$ levels did not affect chip color. In conclusion, tuber dry mass could be reduced by $N$ levels and fertilization practices should be adjusted to produce potato tubers for industry.

Key words: Solanum tuberosum, chips, mineral nutrition, dry matter.

A batata é a hortaliça de maior importância econômica no Brasil, sendo a fritura na forma de chips a forma preferencial de preparo, tanto comercial quanto doméstico (ZORZELLA et al., 2003). O teor de matéria seca, também conhecido como gravidade específica, é uma das variáveis determinantes da qualidade de fritura dos tubérculos, porque determina a absorção de óleo

\footnotetext{
${ }^{1}$ Programa de Pós-graduação em Agronomia, Departamento de Fitotecnia, Universidade Federal de Santa Maria (UFSM), Santa Maria, RS, Brasil.

${ }^{2}$ Departamento de Fitotecnia, UFSM, 97105-900, Santa Maria, RS, Brasil. E-mail: andriolo@ccr.ufsm.br. Autor para correspondência. ${ }^{3}$ Departamento de Fitotecnia, UFSM, Santa Maria, RS, Brasil.

${ }^{4}$ Curso de Agronomia, UFSM, Santa Maria, RS, Brasil.
} 
durante a fritura, a textura, o sabor e o rendimento de chips (CAPÉZIO et al., 1993). Teores elevados de matéria seca conferem maior crocância e diminuem a absorção de óleo. O teor de matéria seca dos tubérculos destinados ao processamento na forma de chips deve ser de, pelo menos $20 \mathrm{~g} 100 \mathrm{~g}^{-1}$, o que corresponde a uma gravidade específica em torno de $1,081 \mathrm{~g} \mathrm{~cm}^{-3}$. Teores superiores a $24 \%$ são indesejados porque produzem fatias quebradiças e causam desgaste excessivo das máquinas fatiadoras (POPP, 2000).

Os açúcares redutores servem de substrato para a reação de Maillard, que resulta no escurecimento não enzimático dos chips, reduzindo a aceitação comercial (COELHO et al., 1999). Teores de açúcares redutores inferiores a $0,1 \%$ indicam que a cultivar é boa para fritura. Entre $0,1 \%$ e $0,3 \%$, indicam que a qualidade do tubérculo é razoável, porém sujeita a algum grau de escurecimento. Acima de $0,3 \%$ o produto não é adequado para a fritura (MELO, 1997).

O excesso de nitrogênio prolonga o ciclo de crescimento e desenvolvimento da cultura e reduz a gravidade específica dos tubérculos, favorecendo o escurecimento e a maior retenção de gordura nos chips (STARK et al., 2003). O N prolonga o período de tuberização da cultura, o que implica a produção de tubérculos com diferentes idades fisiológicas na mesma planta. Conseqüentemente, ao serem colhidos, os tubérculos podem apresentar diferentes graus de maturidade, com baixa gravidade específica naqueles ainda imaturos. Esses tubérculos, quando submetidos à fritura, apresentam coloração mais escura do que tubérculos colhidos maduros (BRIERLEY et al., 1997). São escassas as informações de pesquisas sobre o efeito do nitrogênio na qualidade dos tubérculos de batata destinados ao processamento na forma de chips.

O objetivo do trabalho foi determinar a influência da disponibilidade de nitrogênio durante o ciclo de crescimento e desenvolvimento da cultivar Asterix de batata no teor de matéria seca dos tubérculos e na coloração dos chips.

A implantação da cultura foi realizada no dia 02 de Setembro de 2003 na área experimental do Departamento de Fitotecnia da Universidade Federal de Santa Maria, RS, com a cultivar Asterix. O plantio foi efetuado em sacolas de polietileno contendo $4,4 \mathrm{dm}^{3}$ de substrato comercial orgânico (Plantmax Ha ${ }^{\circledR}$ ), sobre camalhões cobertos com filme de polietileno opaco de $100 \mu \mathrm{m}$ de espessura, em um arranjo de $1 \mathrm{~m}$ entre fileiras e $0,30 \mathrm{~m}$ entre plantas. Sobre cada sacola foi colocado um tubo gotejador, com vazão de $1,3 \mathrm{~L} \mathrm{~h}^{-1}$ e o conjunto formado pelas sacolas e tubos gotejadores foi coberto com filme opaco de polietileno dupla face, para reduzir a evaporação superficial e evitar a incidência direta dos raios solares sobre o substrato. O volume de água retido em cada sacola na capacidade máxima de retenção de água foi de $1.250 \mathrm{~mL}$. A água e os nutrientes foram fornecidos diariamente através da fertirrigação, sempre que necessário para repor os volumes de água consumidos pela transpiração, estimados a partir de dados sobre o consumo de água de hortaliças cultivadas no mesmo local (DALSASSO et al., 1997), convertidos por unidade de radiação solar e de área foliar da cultura.

Os tratamentos foram constituídos por cinco concentrações de N na solução nutritiva: 5,0 (T1), 8,3 (T2), 11,3 (T3), 14,3 (T4) e 16,3mmol L-1 (T5). Os demais macronutrientes foram fornecidos nas mesmas concentrações para os cinco tratamentos, de 8,3 de $\mathrm{K}^{+}$; 3,5 de $\mathrm{Ca}^{++} ; 1,4$ de $\mathrm{Mg}^{++} ; 1,4$ de SO$_{4}^{-}$e 1,2 $\mathrm{mmol} \mathrm{L}^{-1}$ de $\mathrm{H}_{2} \mathrm{PO}_{4}^{-}$e os micronutrientes de 0,03 de $\mathrm{Mo}$; 0,26 de B; 0,06 de Cu, 0,50 de Mn, 0,22 de Zn e 1,0mg L-1 de Fe. A condutividade elétrica foi de 1,7; 1,87; 2,19; 2,51 e 2,72dS m ${ }^{-1}$ nos tratamentos T1 a T5, respectivamente. $\mathrm{O} \mathrm{pH}$ situou-se entre os limites de 5,3 e 6,0. O delineamento experimental foi o inteiramente casualizado, com três repetições de 25 sacolas.

Os tubérculos foram colhidos no dia 17 de dezembro de 2003, aos 104 dias após o plantio, após ter sido atingida a senescência, correspondente ao estádio 87 da escala de BÄTZ et al. (1980). Após a colheita, foram lavados e deixados em processo de cura durante 15 dias, na temperatura de $20^{\circ} \mathrm{C}$, sendo a seguir realizadas as determinações da matéria seca e coloração dos chips. O teor de matéria seca foi determinado pela razão, expressa em porcentagem, entre a matéria fresca e seca dos tubérculos, após secagem em estufa de circulação forçada de ar, à temperatura de $60^{\circ} \mathrm{C}$, até massa constante. Para as determinações da coloração dos chips, os tubérculos foram divididos ao meio no sentido transversal e cortados em fatias de espessura entre 2,5 a 3,0 x 10mm, fritando-se apenas as duas fatias centrais. A fritura foi feita em óleo de soja refinado, sob temperatura de $180^{\circ} \mathrm{C}$, até cessar a borbulha, em fritadeira industrial (Top Taylor TTF-35-G) sendo a temperatura do óleo monitorada com um termômetro de bulbo de mercúrio. Após a fritura, a coloração dos chips foi determinada através de um colorímetro digital (Minolta CR-300), com duas repetições de cada amostra.

O teor de matéria seca dos tubérculos aumentou da primeira até a terceira dose, decrescendo a seguir segundo um modelo polinomial (Figura 1A). Os valores ao final do experimento foram de 19,5; 20,5; 20,8; 18,6 e 18,4 g 100 $\mathrm{g}^{-1}$ nas doses de T1 a T5, respectivamente, com uma diminuição de $11,5 \%$ entre T3 e T5. Estes resultados indicam que somente os tubérculos das doses T2 e T3 atingiriam o teor mínimo 
de matéria seca preconizado pela literatura, que é de $20 \mathrm{~g} 100 \mathrm{~g}^{-1}$ (DAHLENBURG et al., 2001). Não foi observada relação do teor de açúcares redutores e da coloração dos chips com as doses de $\mathrm{N}$ fornecidas (Figura 1B e Figura 1C).

Resultados da literatura sobre o efeito do $\mathrm{N}$ no teor de matéria seca dos tubérculos de batata são contraditórios. Em lavouras nos Estados Unidos, foi observada redução do teor de matéria seca e aumento na oleosidade dos chips por efeito de doses de nitrogênio nas cultivares Kennebec, White Rose, Norgold Russet e Cascade (KUNKEL \& HOLSTAD, 1972). Entretanto, DAHLENBURG et al. (2001) relatam aumento no teor de matéria seca na cultivar Kennebec com doses de $\mathrm{N}$ de até $350 \mathrm{Kg} \mathrm{ha}^{-1}$ e MAIER et al. (2001) observaram aumento na matéria seca com doses superiores a $369 \mathrm{Kg} \mathrm{ha}^{-1}$. Os resultados atuais indicam diminuição no teor de matéria seca dos tubérculos sob altas doses de N. Nessas doses, é possível que o teor mais baixo de matéria seca esteja relacionado com a idade fisiológica dos tubérculos, pois é conhecido na literatura o efeito do N no retardamento da tuberização e da maturação dos tubérculos (BRIERLEY et al., 1997; STARK et al., 2003). Entretanto, se o efeito sobre o teor de matéria seca fosse devido somente a esse fator, os tubérculos provenientes das plantas que receberam as doses mais baixas de $\mathrm{N}$ deveriam ter apresentado os valores mais elevados para essa variável, pois nessas plantas tanto a duração do ciclo quanto do período de tuberização e o número de tubérculos foram menores do que naquelas que receberam a dose mais elevada de N. Essa hipótese não é confirmada pelos resultados deste trabalho (Figura 1A), pois não foram observadas diferenças significativas nas médias do teor de matéria seca dos tubérculos das plantas que receberam as três doses menores de N. Dessa forma, a hipótese de um efeito direto do $\mathrm{N}$ sobre o teor de matéria seca dos tubérculos não pode ser descartada.

Com relação à coloração dos chips, os resultados reforçam observações anteriores feitas por SPARROW \& CHAPMAN (2003), os quais concluíram que os efeitos do $\mathrm{N}$ sobre a coloração do chips são pequenos e de reduzida importância comercial. Isso significa que os efeitos do $\mathrm{N}$ ocorreriam de forma predominante no equilíbrio entre o crescimento da parte aérea e dos tubérculos, o qual determina a partição da matéria seca entre esses dois compartimentos da planta. O escurecimento dos chips é um processo influenciado principalmente pelo teor de açúcares redutores, o qual ocorreria após o transporte dos assimilados da parte aérea para os tubérculos, não sendo por isso afetado diretamente pela disponibilidade de $\mathrm{N}$ para a fotossíntese. Entretanto, afeta de forma indireta ao interferir na maturidade dos tubérculos e na partição de matéria seca entre a parte vegetativa e os tubérculos.

Os resultados indicam que o $\mathrm{N}$ pode reduzir o teor de matéria seca , porém não afeta a coloração dos chips dos tubérculos da cultivar Asterix destinados



Figura 1 -Teores de matéria seca (A), açúcares redutores (B) e coloração dos chips (C) de tubérculos de batata da cv. Asterix produzidos sob cinco concentrações de nitrogênio $\left(5,0 ; 8,3 ; 11,3 ; 14,3\right.$ e $\left.16,3 \mathrm{mmolN} \mathrm{L}^{-1}\right)$ na solução nutritiva. Santa Maria, UFSM, 2004.

Ciência Rural, v.36, n.2, mar-abr, 2006. 
ao processamento. O manejo da adubação nitrogenada visando somente à produtividade de tubérculos, como praticado na produção para consumo in natura, não é adequado para o processamento industrial. Nesse caso, critérios específicos de manejo da adubação nitrogenada devem ser observados levando em conta também o teor de matéria seca.

\section{AGRADECIMENTOS}

À Fundação de Amparo a Pesquisa do Estado do Rio Grande do Sul (FAPERGS), pelo apoio financeiro ao projeto, processo 01/1704.5.

\section{REFERÊNCIAS}

BATZ, W. et al. Entwicklungsstadien der Kartoffel. Berlin Biologische Bundesanstalt fur Land-und Forstwirtschaft, 1980. 7p.

BRIERLEY, E.R. et al. Aspects of amino acid metabolism in stored potato tubers (cv. Pentland Dell). Plant Science, v.127, p.17-24, 1997.

CAPÉZIO, S. et al. Selección por peso especifico en generaciones tempranas en el mejoramiento de la papa. Revista Latinoamericana de la Papa, v.6, p.54-63, 1993.

COELHO, A.R. et al. Qualidade de batata (Solanum tuberosum L.) para fritura, em função dos níveis de açúcares redutores e de amido, durante o armazenamento refrigerado e à temperatura ambiente com atmosfera modificada. Ciência e Agrotecnologia, Lavras, v.23, n.4, p.899-910, 1999.

DAHLENBURG, A.P. et al. Effect of nitrogen on the size, specific gravity, crisp colour and reducing sugar concentration of potato tubers (Solanum tuberosum L.) cV.
Kennebec. 2001. Acesso em: 07 de Junho de 2004. On line. Disponível em: http://www.sardi.s.gov.au.

DALSASSO, L.C.M. et al. Consumo de água do tomateiro tipo salada em estufa plástica. Revista Brasileira de Agrometeorologia, v.5, n.1, p.61-67, 1997.

KUNKEL, R.; HOLSTAD, N. Potato chip color, specific gravity and fertilization of potatoes with N, P, K. American Potato Journal, v.49, p.43-62, 1972.

MAIER, N.A. et al. Effect of nitrogen, phosphorus and potassium on yield, specific gravity, crisp colour and tuber chemical composition of potato (Solanum tuberosum L.) cv. Kennebec. 2001. Acesso em: 07 de Junho de 2004. On line. Disponível em: http://www.sardi.s.gov.au.

MELO, P.E. Aptidão de cultivares de batata para consumo in natura e para processamento. In: SEMINÁRIO DE ATUALIZAÇÃO NA CULTURA DA BATATA, 1997, Santa Maria, RS. Anais... Santa Maria: Sociedade de Agronomia de Santa Maria, 1997. p.76.

POPP, P. Industrialização da batata no Brasil. In: WORKSHOP BRASILEIRO DE PESQUISA EM MELHORAMENTO DE BATATA, 1996, Londrina, PR. Anais... Brasília: EMBRAPA Hortaliças, 2000. p.35.

SPARROW, L.A. ; CHAPMAN, S.R. Effects of nitrogen fertilizer on potato (Solanum tuberosum L., cv. Russet Burbank) in Tansmania. Australian Journal of Experimental Agriculture, v.43, n.6, p.631-641, 2003.

STARK, J. et al. Tuber quality. 2003. Capturado em 04 de jul. 2004. Online. Disponível na Internet www.ag.uidaho.edu/ potato/production/files.

ZORZELLA, C. et al. Caracterização física, química e sensorial de genótipos de batata processados na forma de chips. Brazilian Journal of Food Technology, v.6, p.15-24, 2003. 